\title{
ANALISA PEGARUH MEDIA VARIAN PASIR DAN BUTIRAN PASIR TERHADAP KEMATANGAN PENGGORENGAN KRUPUK UPIL
}

\author{
Esa Andriyanto Putra \\ Teknik Mesin, Fakultas Teknik \\ Universitas Maarif Hasyim Latif, Sidoarjo, Indonesia \\ e-mail : esa-andriyanto-putra@student.umaha.ac.id
}

\begin{abstract}
ABSTRAK
Kerupuk upil merupakan salah satu jenis makanan ringan yang proses penggorengannya menggunakan pasir, yang ketersediaannya sangat melimpah dan gampang didapat namun masih jarang untuk memanfaatkannya pada di dalam industri pangan, hal ini dapat oleh karena disebabkan kurangnya informasi dalam kemampuan dan potensi pasir dalam media untuk penghantar panas. Didalam hantaran daya panas satu bahan dapat menentukan efisiesi penggorengan kerupuk upil, untuk pengolahan kerupuk upil sangat memerlukan adanya wawasan dalam suatu proses penggoregan kerupuk upil tentang daya penghantar panas, tentang media yang digunakan dalam proses penggorengan. Maka dari itu penulis melakukan penelitian untuk mengetahui hasil analisa pengaruh media variasi pasir dan butiran pasir terhadap kematangan penggorengan kerupuk upil. Jenis pasir yang digunakan adalah pasir kali dan psir pantai yang memiliki ukuran 10 mesh, 14 mesh, dan 18 mesh , yang menyebabkan penulis mengira adanya ukuran yang berbeda, maka nilai perambatan daya hantar panas pun berbeda. Dalam penelitian ini metode yang digunakan adalah metode kualitatif yang bersifat deskriptif. Dari hasil penelitian didapatkan Suhu yang ideal untuk suatu penggorengan krupuk upil adalah pada suhu $200^{\circ} \mathrm{C}$ dengan waktu rata matang suatu krupuk 50 detik.
\end{abstract}

Kata kunci: Suhu, Varian pasir, Waktu

\section{PENDAHULUAN}

Kerupuk upil merupakan salah satu jenis makanan ringan yang proses penggorengannya menggunakan pasir, makanan ini akrab dengan lidah masyarakat Indonesia dikarenakan mempunyai rasa yang berbeda apabila digoreng dengan minyak. bahkan, risiko untuk melempem dapat ditekan karena dapat didaur ulang kelebihan lain kerupuk upil adalah bebas kolesterol dan baik untuk dikonsumsi setiap hari.

Kerupuk upil merupakan penghasilan utama mayoritas penduduk di Desa Gampang Kecamatan Prambon Kabupaten Sidoarjo Kerupuk upil merupakan penghasilan utama mayoritas penduduk di Desa Gampang Kecamatan Prambon Kabupaten Sidoarjo salah satu UKM pengoreng kerupuk upil. Proses penggorengan masih dilakukan secara manual dan ukuran tempat menggorengnya kecil. Selain itu, kekurangan dari alat ini yaitu masih menggunakan tongkat pengaduk dari kayu untuk meratakan dan mengeluarkan kerupuknya masih terdapat pasir yang ikut terbawa keluar sehingga dibutuhkan kerja 2 kali untuk memisahkan kerupuk dari pasirnya dengan pengayak.

Dalam 1 hari Proses Penggorengan kerupuk upil para pekerja hanya mampu menghasilkan $80 \mathrm{~kg}$ kerupuk, sementara tingkat permintaan pasar melebihi jumlah tersebut. Proses terpenting pada Penggorengan adalah membutuhkan waktu yang cepat, serta efektif kami merancang suatu alat Penggoreng Kerupuk Upil Dengan Screw Dilengkapi Pembalik Putaran dengan system pengaduk screw yang bisa berputar kanan maupun kiri sesuai durasi waktu yang bisa ditentukan sendiri oleh timer off dengan tambahan plat berlubang untuk memisahkan antara pasir dengan kerupuk ketika keluar dari drum penggorengan guna mempercepat waktu penggorengan.

Tujuan dari pembahasan penelitian ini adalah:

1. Untuk mengetahui hasil analisa pengaruh media variasi pasir terhadap kematangan penggorengan kerupukupil.

2. Untuk mengetahui hasil analisa pengaruh butiran pasir terhadap kematangan penggorengan kerupuk upil.

Langkah - langkah penggorengan kerupuk upil secara manual

selama ini dalam dunia kuliner khususnya pengusaha kerupuk goreng upil skala rumah tangga (kecil) proses penggorengannya masih mengunakan peralatan penggorengan tradisional yang menggunakan wajan yang ditaruh diatas kompor dengan media pasir panas dan pengaduk sederhana yang memerlukan waktu proses penggorengan lebih lama serta hasil kurang maksimal 
Langkah-langkah proses penggorengan kerupuk upil secara manual dan sederhana;

1. Mempersiapkan peralatan menggoreng kerupuk upil meliputi : kompor, wajan serta pasirnya, peniris, pengaduk dan pasir sebagai media pengganti minyak goring

2. Panaskan pasir diatas wajan selama 20 menit hingga kadar airnya menguap dan kering hingga suhunya kurang lebih 200 derajat celcius

3. Masukan kerupuk mentah yang sudah dijemur kedalam wajan yang berisikan pasir panas

4. Aduk dan ratakan kerupuk mentah dengan pasir panas agar matangnya merata dan mengembang sempurna.

5. Bila sudah mengembang sempurna angkat kerupuk dengan peniris dan goyanggoyangkan agar pasirnya turun kembali kewajan

Drum penggoreng kerupuk

Tempat untuk menggoreng kerupuk dengan media pasir panas dibutuhkan drum dari stainless steel sebagai tempat penggorenganya, pada dasarnya menerapkan rumus keliling lingkaran yang ukuranya ditentukan sesuai kapasitas penggorengan bahan baku kerupuk.

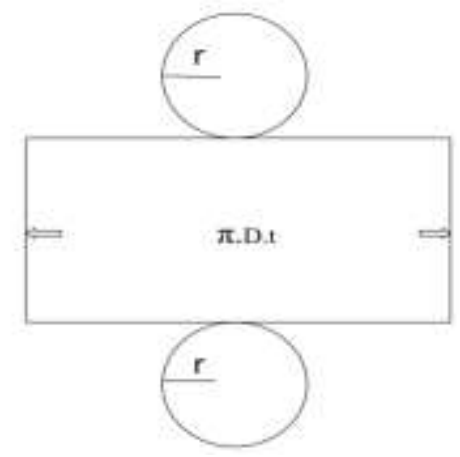

Gambar 1. Bukaan Tabung

Luas selimut tabung

$$
\pi . D . \mathrm{t}
$$

Volume tabung

Keliling lingkaran

$$
\frac{\pi}{4} \cdot D^{2} \cdot t
$$

Keterangan:

$$
\begin{array}{ll}
\pi & =3.14 \\
\mathrm{D} & =\text { diameter } \\
\mathrm{t} & =\text { tinggi }
\end{array}
$$

Berat drum berbahan stainless stell 304 agar lebih tahan karat, untuk menentukan berat drum rotary maka rumus perhitunganya;

Keterangan:

$$
\mathrm{W}=\mathrm{S} X \mathrm{~V}
$$

$\mathrm{W}=$ specific gravity $\mathrm{x}$ volume

berat benda $(\mathrm{kg})=$ berat jenis $\mathrm{x}$ volume $(\mathrm{dm} 3)$

berat jenis stainless steel $7900 \mathrm{~kg} / \mathrm{m} 3$
METODE PENELITIAN

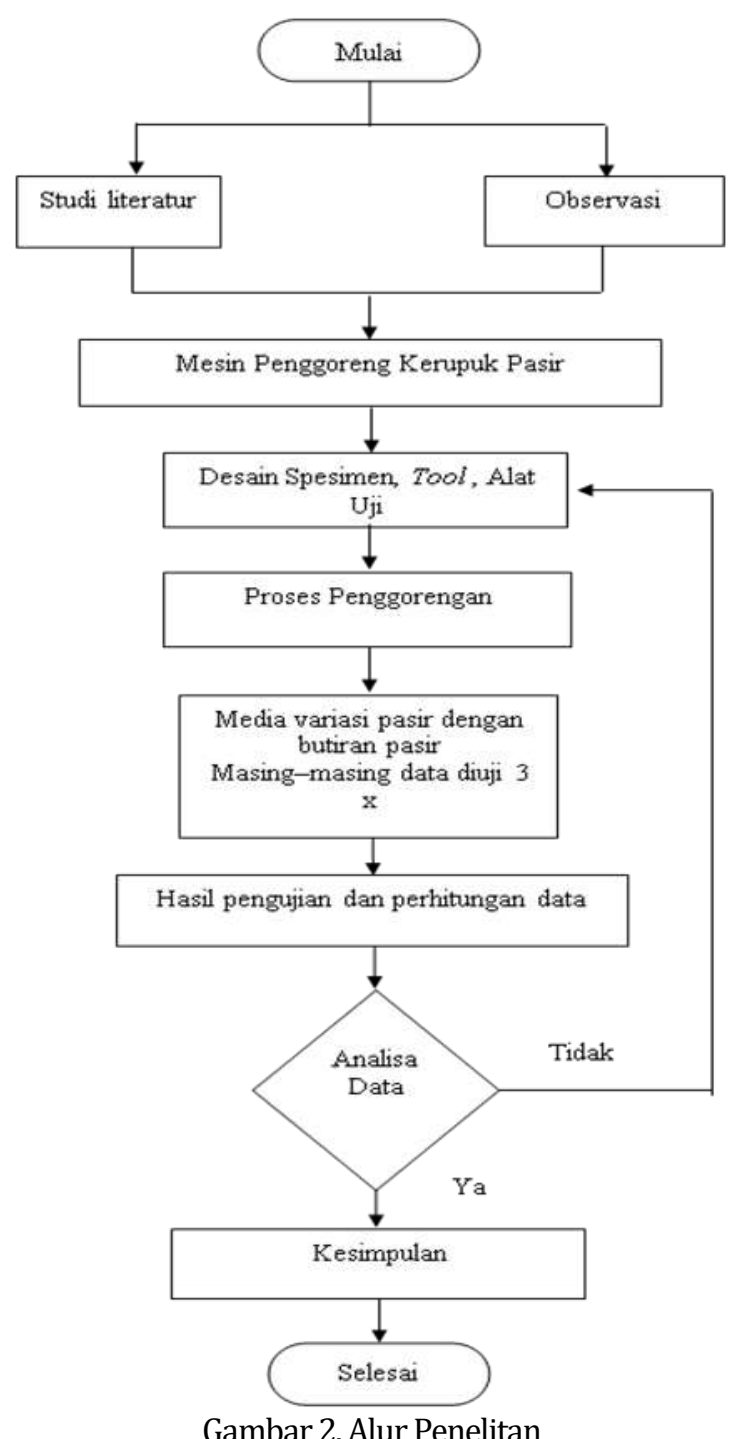

Rancangan Mesin yang di Analisa

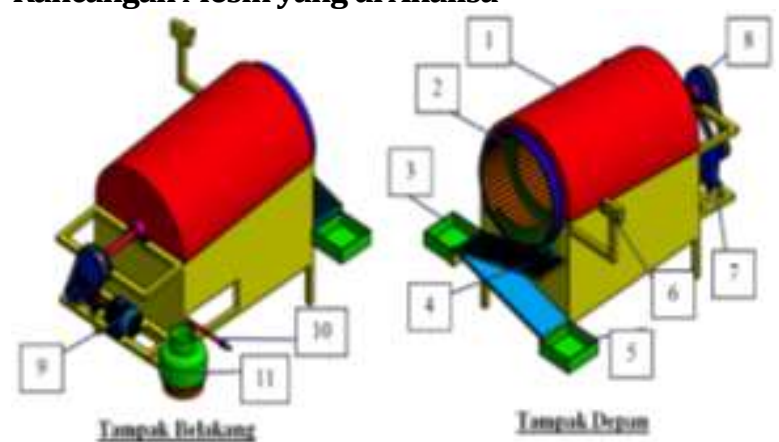

Gambar 2. Gambar Rancangan Mesin Penggoreng Kerupuk Upil

Keterangan Gambar;

1. Penutup atas (cover) berfungsi sebagai pengarah dan pengaman panas dari Drum Rotary yang terbuat dari lembaran seng yang berisikan insulasi rockwool sebagai peredam panasnya

2. Drum rotary berfungsi sebagai tempat penggorengan kerupuk yang didalamnya berisikan pasir panas yang 
berputar dan terdapat screw pengaduk dan pendorong keluar ketika sudah matang

3. Wadah kerupuk yang sudah matang agar kerupuknya tidak tercecer dan tetap bersih

4. Plat berlubang Pemisah pasir berfungsi sebagai penyaring antara kerupuk yang sudah matang dengan pasir penggoreng yang ikut terbawa saat proses pengeluaran

5. Penampung pasir berfungsi sebagai penampung pasir yang ikut keluar agar tidak jatuh dan terbuang

6. Panel Control berfungsi sebagai tempat rangkaian listrik pengontrol arah putaran motor AC yang memutar Drum rotary untuk proses penggorengan dan pengeluaran

7. Gear box berfungsi untuk mereduksi putaran motor agar sesuai kebutuhan untuk memutar Drum Rotary

8. Pulley sebagai penyalur daya putaran motor yang telah direduksi gear box menuju Drum rotary

9. Motor pemutar Drum Rotary penggoreng kerupuk pasir yang bisa berputar bolak-balik

10. Kompor pemanas Drum rotary yang bisa diatur dengan manual sesuai kapasitas kerupuk yang digoreng

11. Tempat tabung gas LPG

\section{Langkah - langkah Analisa Data Penelitian}

Langkah-langkah yang dilakukan adalah :

1. Memvariasikan media pasir dan butiran pasir terhadap waktu dan suhu:

2. Melakukan pengambilan data kerupuk hasil penggorengan berdasarkan variabel data yang telah diambil.

\section{HASIL DAN PEMBAHASAN}

Penentuan Volume Tabung Penggoreng

a. Dari hasil Percobaan 2 jenis ukuran kerupuk :

Diameter kerupuk sebelum di goreng $8 \mathrm{~cm}$ setelah digoreng menjadi diameter $8,5 \mathrm{~cm}$

Diameter kerupuk sebelum di goreng $5 \mathrm{~cm}$ setelah digoreng menjadi diameter $5,5 \mathrm{~cm}$

b. Volume penggorengan ideal adalah maksimal $1 / 3$ volume tabung untuk hasil lebih optimal kematangan kerupuk, pasir tidak tumpah keluar, dan berat kerupuk mencapai 4 ons.

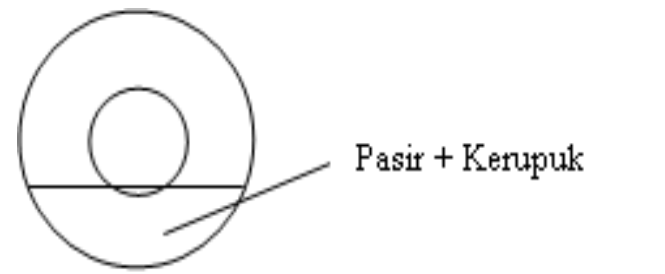

Gambar 3. Penggorengan ideal 1/3 volume tabung

Menghitung luasan dan berat Drum luar Dengan rumus lingkaran

a. Luas Tutup Belakang dengan bahan plat besi

$$
=3.14 / 4 \times 772 \mathrm{~cm}
$$

$=4654,26 \mathrm{~cm} 2$

Berat Plat

$=4,7 \mathrm{~m} \times 0.0010 \mathrm{~m} \times 0,8 \mathrm{~m} \times 7850 \mathrm{~kg} / \mathrm{m} 3$

$=28 \mathrm{~kg}$

b. Selimut tabung Luar dengan bahan plat besi

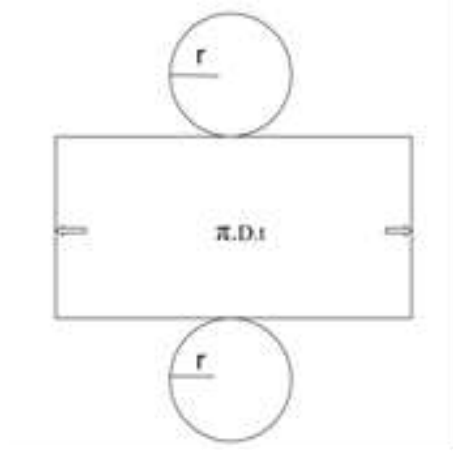

Gambar 4. Selimut Tabung

Luas Selimut Tabung

$=\pi$.D.t

$=3.14 \times 0,77 \mathrm{~m} \times 0,8 \mathrm{~m}$

$=1,9 \mathrm{~m} 2$

Berat Plat

$$
\begin{aligned}
& =1,9 \mathrm{~m} 2 \times 0,0010 \mathrm{~m} \times 7850 \mathrm{~kg} / \mathrm{m} 3 \\
& =12 \mathrm{~kg}
\end{aligned}
$$

Menghitung luasan dan berat Drum luar Dengan rumus lingkaran

a. Selimut tabung dalam dengan bahan Stainless steel tipe 304

$$
\begin{aligned}
\pi / 4 . \mathrm{D} 2=3.14 / 4 \times 732 \mathrm{~cm} & \\
& =4183,26 \mathrm{~cm} 2 \\
\text { Berat Plat } & =4,18 \mathrm{~m} \times 0.0010 \mathrm{~m} \times 0.83 \mathrm{~m} \mathrm{x} \\
7900 \mathrm{~kg} / \mathrm{m} 3 & \\
& =27 \mathrm{~kg}
\end{aligned}
$$

b. Luasan dan berat plat Screw berbentuk lingkaran dengan Stainless steel tipe 304

$$
\begin{aligned}
& ((\text { phi }) \pi / 4 . \mathrm{D} 2)-((\text { phi }) \pi / 4 . \mathrm{D} 2) \\
& =(0.785 \times 0.533)-(0.785 \times 0.185) \\
& =0.434105 \mathrm{~m} 2-0.145225 \mathrm{~m} 2 \\
& =0.28888 \mathrm{~m} 2 \\
& \text { Berat Plat } \\
& =0.29 \mathrm{~m} 2 \times 0.0010 \mathrm{~m} \times 7900 \mathrm{~kg} / \mathrm{m} 3 \\
& =2.3 \mathrm{~kg} \times 3 \\
& =7 \mathrm{~kg}
\end{aligned}
$$

c. Luasan dan berat plat penyanga drum berbentuk lingkaran

(phi) $\pi / 4$. D2 . $\mathrm{t}=0.785 \times 0.030 \mathrm{~m} \times 0.05 \mathrm{~m}$

$=0.785 \times 0.0090 \mathrm{~m} \times 0.05 \mathrm{~m} \times 7900 \mathrm{~kg} / \mathrm{m} 3$

$=2.7 \mathrm{~kg}$

Perhitungan kebutuhan Torsi motor dengan menghitung berat Drum

a. Berat Drum

$$
\begin{aligned}
& =28 \mathrm{~kg}+12 \mathrm{~kg}+27 \mathrm{~kg}+7 \mathrm{~kg}+2.7 \mathrm{~kg} \\
& =76.7 \mathrm{~kg}
\end{aligned}
$$

b. Berat Pasir $=20 \mathrm{~kg}$

c. Berat total $=$ Berat Drum + Berat Pasir

$$
=96.7 \mathrm{~kg}
$$

d. Rumus mencari torsi yang Digunakan 


$$
\begin{aligned}
& \text { f(total) }=\mathrm{f} 1+\mathrm{f} 2 \\
& =76,7 \mathrm{Kg}+20 \mathrm{Kg} \\
& =96,7 \mathrm{Kg} \\
& \quad \mathbf{T}=\mathbf{f}(\text { Total }) \cdot \mathbf{r} \\
& =(96.7 \mathrm{~kg} \times 9,8 \mathrm{~m} / \mathrm{s} \times 0,38 \mathrm{~m}) \\
& =360 \mathrm{Nm}
\end{aligned}
$$

Rasio Gearbox yang dipakai $=15: 1$

Perhitungan Torsi Motor

Daya Yang Digunakan $1 \mathrm{Hp}$

$$
\begin{gathered}
T=\frac{60 \cdot P}{2 \pi \cdot n} \\
T=\frac{60.745,7}{2.3,14 \cdot 1500} \\
T=\frac{44742}{9420} \\
T=4,75 \mathrm{Nm}
\end{gathered}
$$

Perhitungan Rasio Gearbox Ratio

$$
\frac{\mathrm{n} 1}{\mathrm{n} 2}
$$

Jika Putaran yang di inginkan adalah 100 Rpm maka

$$
\text { Ratio }=\frac{1500 \mathrm{rpm}}{100 \mathrm{rpm}}=15
$$

Perhitungan Rasio Sprocket

$$
\frac{\mathrm{n} 1}{\mathrm{n} 2}=\frac{\mathrm{d} 2}{\mathrm{~d} 1}
$$

Untuk menurunkan rpm sesuai dengan rpm drum yang di inginkan

$$
\frac{100 \mathrm{rpm}}{40 \mathrm{rpm}}=\frac{15 \mathrm{gigi}}{40 \mathrm{gigi}}
$$

Maka rasio gear sprocket yang dibutuhkan adalah 2,6 Rasio Gearbox dan sprocket

Rasio gearbox = $15: 1$

Rasio Sprocket $=2,6: 1$

Torsi motor yang dayanya diteruskan gearbox

$$
\begin{aligned}
\mathrm{T} & =4,8 \mathrm{Nm} \times 15 \text { Rasio } \\
& =72 \mathrm{Nm}
\end{aligned}
$$

Putaran motor yang direduksi Gearbox

$$
\frac{1500 \mathrm{rpm}}{15 \text { (ratio) }}=100 \mathrm{rpm}
$$

Torsi gearbox yang dayanya diteruskan sprocket

$$
\begin{aligned}
\mathrm{T} & =4,8 \mathrm{Nm} \times 17,6 \text { Rasio } \\
& =84,5 \mathrm{Nm}
\end{aligned}
$$

Putaran gearbox yang direduksi sprocket

$$
\frac{100 \mathrm{rpm}}{2,6 \text { (ratio) }}=38,5 \mathrm{rpm}
$$

Maka didapatkan putaran $38.5 \mathrm{rpm}$ dengan torsi 84,5 Nm Torsi yang dibutuhkan untuk memutar drum adalah $360 \mathrm{Nm}$ sedangkan rpm nya adalah $38.5 \mathrm{rpm}$.

1. Penentuan Temperatur Panas

Dari hasil uji coba, temperatur yang sesuai untuk proses penggorengan kerupuk upil $170^{\circ} \mathrm{C}-200^{\circ} \mathrm{C}$. Dengan laju energi rata - rata 0,1845 Joule/s. Maka proses pemanasan untuk mesin penggorengan kerupuk upil laju energi rata - rata yaitu :

Rumus

$$
\begin{aligned}
& \text { Keterangan : } \\
& \mathrm{P}=\text { Laju energy rata }- \text { rata (Joule/s) } \\
& \mathrm{e}=\text { Emisivitas } \\
& \sigma=\text { Konstanta Setfan-Boltzman } \\
& 5,67 \times 10^{-8} \mathrm{~m} / \mathrm{mk} \\
& A=\text { Luas permukaan benda }(\mathrm{m}) \\
& \mathrm{T}^{4}=\text { Suhu dalam Kelvin } \\
& \text { Data } \\
& \sigma=5,67 \times 10^{-8}{ }^{\circ} \mathrm{C} \\
& \mathrm{T}=170^{\circ} \mathrm{C}=443^{\circ} \mathrm{K} \\
& e=0,69 \\
& A=0.276
\end{aligned}
$$

Laju energi rata-rata:

$$
\begin{aligned}
P & =e \sigma T^{4} \mathrm{~A} \\
P & =(0,69)\left(5,67 \times 10^{-8}\right)(443)^{4}(0,276) \\
& =0,4245 \text { Joule } / \mathrm{S}
\end{aligned}
$$

2. Percobaan Penggorengan

Penelitian ini akan dilakukan penggorengan kerupuk dengan pasir sebagai media penghantar panas menggunakan mesin penggoreng kerupuk pasir dengan sumber panas dari kompor gas. Pasir yang digunakan dalam penelitian ini adalah pasir kali dengan saringan 10 mesh, 14 mesh dan 18 mesh, kerupuk yang digunakan dalam penelitian ini memiliki ukuran diameter $2,5 \mathrm{~cm}$, ketebalan 1,5 mm dengan berat timbangan kerpuk masing-masing 500 gram. penggorengan kerupuk dilakukan menggunakan suhu $200^{\circ} \mathrm{C}$, sedangkan untuk lama penggorengan terdiri dari 3 yaitu 30,60, dan 90 detik.

Sumber : data percobaan di olah penulis tahun 2019 Dari Tabel 2 dapat dibuat sebuah grafik garis perbandingan antara pasir sungai saringan mesh 10 Mesh, 14 Mesh dan 18 Mesh dan Waktu pada suhu 180 ${ }^{\circ} \mathrm{C}-200{ }^{\circ} \mathrm{C}$ seperti yang dapat dilihat pada Grafik dibawah ini. 


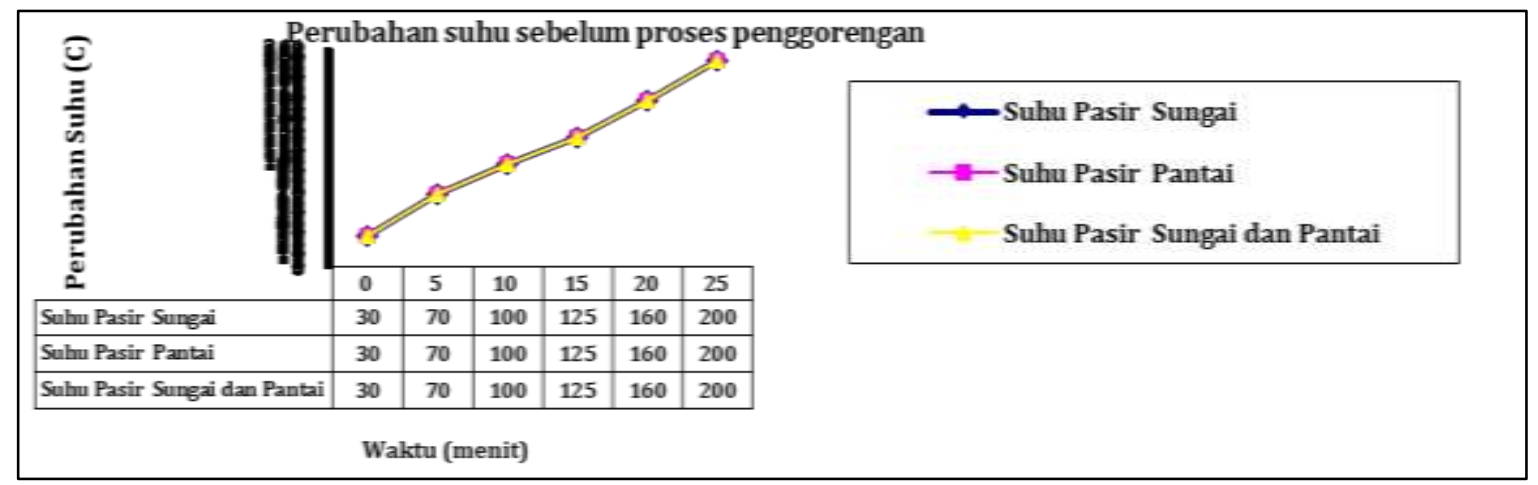

Gambar 5. Grafik Perubahan Suhu Pasir Terhadap Waktu.

Tabel 1. Hasil pengukuran Suhu Pasir Sungai saringan 10 Mesh, 14 Mesh dan 18 Mesh pada suhu $180^{\circ} \mathrm{C}-200^{\circ} \mathrm{C}$.

\begin{tabular}{|c|r|r|r|r|r|r|r|r|r|r|r|r|r|r|r|r|r|r|r|}
\hline Pasir & \multicolumn{110}{c|}{ Waktu (detik) } \\
\cline { 2 - 3 } Sungai & 0 & 5 & 10 & 15 & 20 & 25 & 30 & 35 & 40 & 45 & 50 & 55 & 60 & 65 & 70 & 75 & 80 & 85 & 90 \\
\hline 10 Mesh & 180 & 182 & 184 & 185 & 186 & 187 & 188 & 189 & 190 & 191 & 192 & 193 & 194 & 195 & 196 & 197 & 198 & 199 & 200 \\
\hline 14 Mesh & 180 & 182 & 184 & 186 & 187 & 188 & 189 & 190 & 191 & 192 & 193 & 194 & 195 & 196 & 197 & 198 & 199 & 200 & 200 \\
\hline 18 Mesh & 180 & 182 & 184 & 186 & 187 & 188 & 189 & 190 & 191 & 192 & 193 & 194 & 195 & 196 & 197 & 198 & 199 & 200 & 200 \\
\hline
\end{tabular}

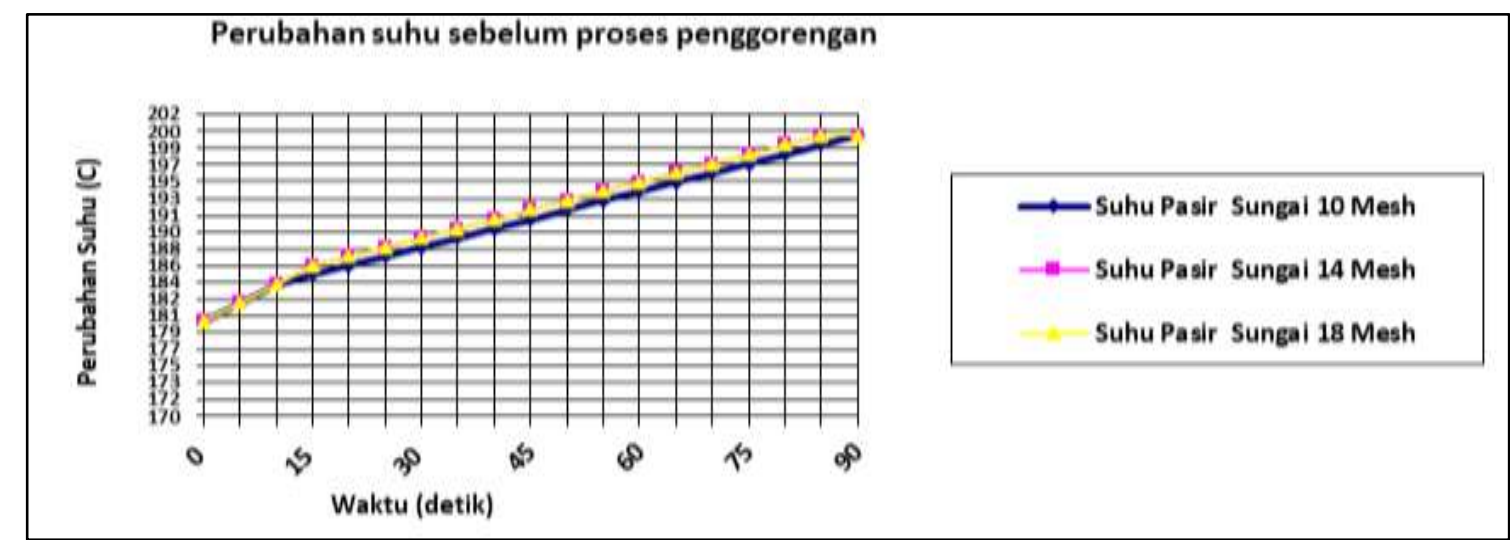

Gambar 6. Grafik Hasil pengukuran Suhu Pasir Sungai saringan 10 Mesh, 14 Mesh dan 18 Mesh pada suhu $180^{\circ} \mathrm{C}-$ $200^{\circ} \mathrm{C}$

Tabel 2 Hasil pengukuran Suhu Pasir pantai saringan 10 Mesh, 14 Mesh dan 18 Mesh pada suhu $180^{\circ} \mathrm{C}-200^{\circ} \mathrm{C}$.

\begin{tabular}{|l|r|r|r|r|r|r|r|r|r|r|r|r|r|r|r|r|r|r|r|}
\hline \multirow{2}{*}{ Pasir Pantai } & \multicolumn{10}{|c|}{ Waktu (detik) } \\
\cline { 2 - 3 } & 0 & 5 & 10 & 15 & 20 & 25 & 30 & 35 & 40 & 45 & 50 & 55 & 60 & 65 & 70 & 75 & 80 & 85 & 90 \\
\hline 10 Mesh & 180 & 183 & 185 & 186 & 187 & 188 & 189 & 190 & 191 & 192 & 193 & 194 & 195 & 196 & 197 & 198 & 199 & 200 & 200 \\
\hline 14 Mesh & 180 & 183 & 185 & 187 & 188 & 189 & 190 & 191 & 192 & 193 & 194 & 195 & 196 & 197 & 198 & 199 & 200 & 200 & 201 \\
\hline 18 Mesh & 180 & 183 & 185 & 187 & 188 & 189 & 190 & 191 & 192 & 193 & 194 & 195 & 196 & 197 & 198 & 199 & 200 & 200 & 201 \\
\hline
\end{tabular}

Sumber : data percobaan di olah penulis tahun 2019

Dari Tabel 2 dapat dibuat sebuah grafik garis perbandingan antara pasir sungai saringan mesh 10 Mesh, 14 Mesh dan 18 Mesh dan Waktu pada suhu $180^{\circ} \mathrm{C}-200^{\circ} \mathrm{C}$ seperti yang dapat dilihat pada Grafik dibawah ini. 


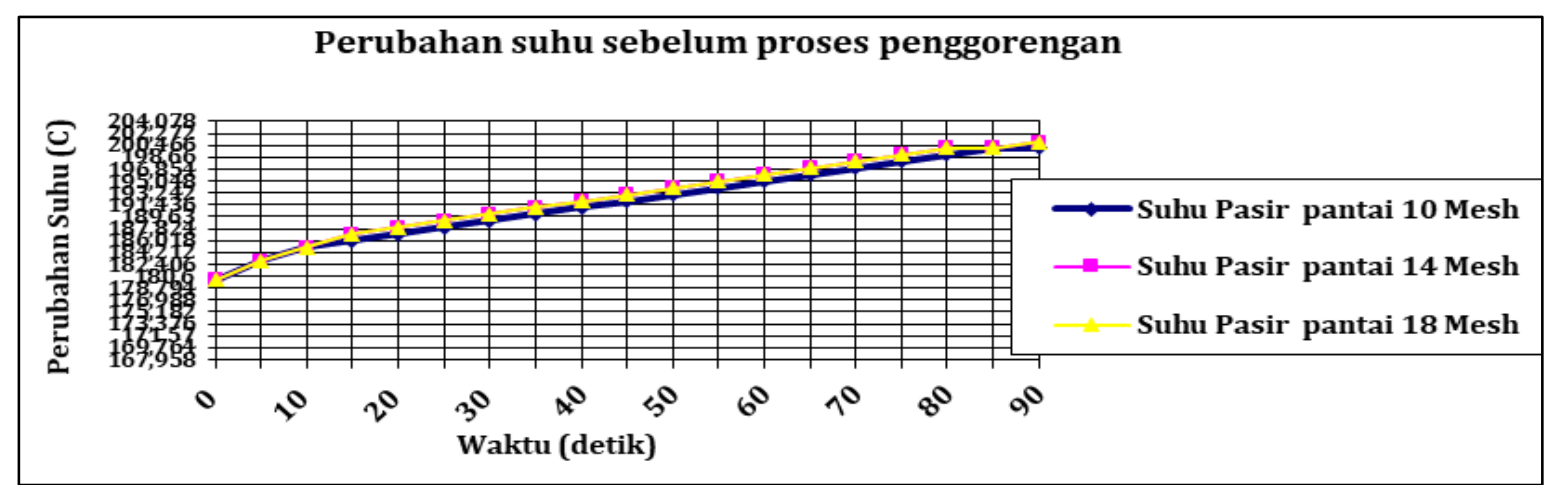

Gambar 7. Grafik Hasil pengukuran Suhu Pasir Pantai saringan 10 Mesh, 14 Mesh dan 18 Mesh pada suhu $180{ }^{\circ} \mathrm{C}-$ $200{ }^{\circ} \mathrm{C}$.

Tabel 3. Hasil pengukuran Suhu Pasir pantai saringan 10 Mesh, 14 Mesh dan 18 Mesh pada suhu $180{ }^{\circ} \mathrm{C}-200{ }^{\circ} \mathrm{C}$.

\begin{tabular}{|l|r|r|r|r|r|r|r|r|r|r|r|r|r|r|r|r|r|r|r|}
\hline $\begin{array}{c}\text { Pasir Sungai } \\
\text { + Pantai }\end{array}$ & \multicolumn{110}{|c|}{5} & 10 & 15 & 20 & 25 & 30 & 35 & 40 & 45 & 50 & 55 & 60 & 65 & 70 & 75 & 80 & 85 & 90 \\
\hline 10 Mesh & 180 & 183 & 185 & 186 & 187 & 188 & 189 & 190 & 191 & 192 & 193 & 194 & 195 & 196 & 197 & 198 & 199 & 200 & 200 \\
\hline 14 Mesh & 180 & 183 & 185 & 187 & 188 & 189 & 190 & 191 & 192 & 193 & 194 & 195 & 196 & 197 & 198 & 199 & 200 & 200 & 201 \\
\hline 18 Mesh & 180 & 183 & 185 & 187 & 188 & 189 & 190 & 191 & 192 & 193 & 194 & 195 & 196 & 197 & 198 & 199 & 200 & 200 & 201 \\
\hline
\end{tabular}

Dari Tabel 3 dapat dibuat sebuah grafik garis perbandingan antara pasir sungai saringan mesh 10 Mesh, 14 Mesh dan 18 Mesh dan Waktu pada suhu $180^{\circ} \mathrm{C}-200^{\circ} \mathrm{C}$ seperti yang dapat dilihat pada Grafik dibawah ini.

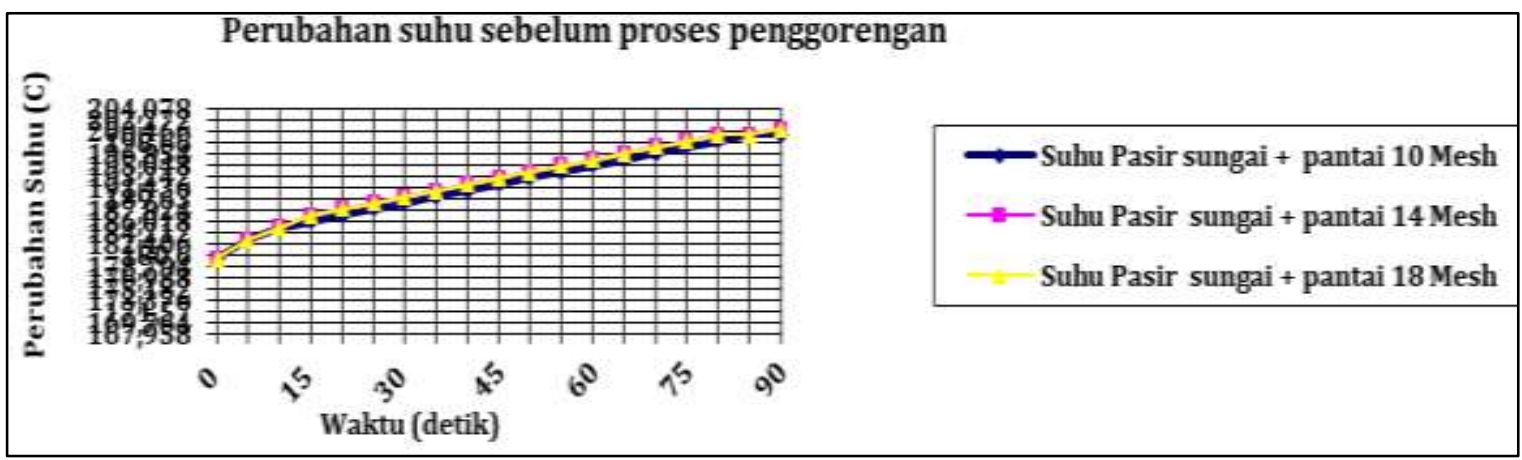

Gambar 8. Grafik Hasil pengukuran Suhu Pasir Sungai dan Pasir Pantai saringan 10 Mesh, 14 Mesh dan 18 Mesh pada suhu $180^{\circ} \mathrm{C}-200^{\circ} \mathrm{C}$

Dari hasil percobaan penggorengan dengan berat kerupuk 50 gram yang digoreng dengan Drum rotary Screw untuk kerupuk upil dengan suhu $200 \stackrel{\circ}{\circ}$ pada waktu 60 detik menggunakan pasir sungai dengan saringan 10 mesh, 14 mesh, dan 18 mesh hasilnya ratarata sangat bagus.

sedangkan hasil percobaan penggorengan dengan berat kerupuk 50 gram yang digoreng dengan Drum rotary Screw untuk kerupuk upil dengan suhu 200 ${ }^{\circ} \mathrm{C}$ menggunakan pasir pantai dengan saringan 10 mesh, 14 mesh, dan 18 mesh cukup dengan waktu 50 detik,

Untuk penggorengan dengan menggunakan pasir sungai + pantai (50\% pasir sungai $+50 \%$ pasir pantai) dengan saringan 10 mesh, 14 mesh, dan 18 mesh cukup dengan waktu waktu 55 detik.

\section{PENUTUP}

\section{Kesimpulan}

Kesimpulan hasil analisa pengaruh media varian pasir dan butiran pasir terhadap kematangan penggorengan kerupuk upil dengan menggunakan mesin penggoreng kerupuk pasir dengan screw dilengkapi pembalik putaran :

1. Dari hasil percobaan di dapatkan untuk 50 gram kerupuk upil di goreng menggunakan pasir sungai dengan saringan 10 mesh, 14 mesh, dan 18 mesh didapatkan waktu ideal penggorengan 60 detik dengan suhu $200^{\circ} \mathrm{c}$ hasilnya sangat bagus.

2. Hasil pengorengan dengan pasir pantai dengan saringan 10 mesh, 14 mesh, dan 18 mesh 
didapatkan waktu ideal penggorengan cukup 50 detik dengan suhu $200^{\circ} \mathrm{c}$ hasilnya sangat bagus.

3. Hasil pengorengan dengan pasir pantai di campur dengan pasir sungai saringan 10 mesh, 14 mesh, dan 18 mesh didapatkan waktu ideal penggorengan cukup 55 detik dengan suhu $200^{\circ}$ c hasilnya sangat bagus.

4. Suhu yang ideal untuk suatu penggorengan krupuk upil adalah pada suhu $200^{\circ} \mathrm{C}$ dengan waktu matang suatu krupuk 50 detik.

\section{Saran}

Perlu adanya kajian terhadap karakteristik pasir pantai lebih lanjut yang layak untuk penggorengan kerupuk upil karena media varian pasir dan butiran pasir mempengaruhi waktu proses kematangan walau sekitar 5 detik.

\section{DAFTAR PUSTAKA}

Afifah, Y. N. (2016). ALIRAN TAK TUNAK FLUIDA NANO MAGNETOHIDRODINAMIK ( MHD ) YANG MELEWATI BOLA.

Afifah, Y. N. (2019). Analysis of Unsteady Magneto Hydro Dynamic (MHD) Nano Fluid Flow Past A Sliced Sphere. IOP Conference Series: Materials Science and Engineering, 494(1). https://doi.org/10.1088/1757899X/494/1/012033

Afifah, Y. N., \& Putra, B. C. (2018). Model Matematika Aliran Tak Tunak Pada Nano Fluid Melewati Bola Teriris Dengan Pengaruh Medan Magnet. Teknika: Engineering and Sains Journal, 2(2), 119-124.

Gunawan, E. et al. (2019) 'Analysis of the Effect of Current Flow Variations in GTAW on SS 400 Plate Material Connected with SUS 304 Stainless Steel Plate Against Tensile Strength and Hardness with ER308L Electrodes', Journal of Physics: Conference Series, 1175(1). doi: 10.1088/1742-6596/1175/1/012277.

Mesin, D. T., Teknik, F., Surabaya, U. N., Mesin, J. T., Teknik, F., \& Surabaya, U. N. (2015). ANALISA DAYA SEBAGAI PENGGERAK PADA MESIN PENGGORENG KERUPUK PASIR SEMIOTOMATIS DILENGKAPI PENGATUR SUHU Agung Prijo Budijono Abstrak Gambar 3. Rancangan Penelitian. 02, 58-63.

Nirwana, L. (2017). Lina Nirwana, Et al / Jurnal Pendidikan Teknologi Pertanian, Vol. 3 (2017) : S182-S196 S182. 3, 182-196.

Pendidikan, J., \& Pertanian, T. (2017). Jumriani K, Et al /Jurnal Pendidikan Teknologi Pertanian, Vol 3 (2017) : S19-S29 S19. 3, 19-29.

Rantawi,(2006). Penggoreng, M., Pasir, K., Otomatis, S., Teknik, F., \& Surabaya, U. N. (n.d.) RANCANG BANGUN MESIN PENGGORENG KERUPUK PASIR SEMI OTOMATIS DILENGKAPI
PENGATUR SUHU Steven.

Rantawi, A. basyir. (2006). Perancangan Unit Transfer (Screw Conveyor) Pada Mesin Pengisi Polibag Untuk Meningkatkan Efektivitas Kinerja Di Bidang Pembibitan. Motivation and Emotion, 30(3), 243-250.

Sularso. (2004). Dasar Perencanaan dan Penelitian. $1-374$.

Sumarji. (2011). Studi Perbandingan Ketahanan Korosi Stainless Steel Tipe SS 304 dan SS 201 Menggunakan Metode U-Bend Test secara Siklik dengan Variasi Suhu dan Ph. Rotor, 4, 18.

Putra, B. C., \& Afifah, Y. N. (2018). Gaussian Mixture Model Untuk Penghitungan Tingkat. Teknika: Engineering and Sains Journal, 2, 53-58.

Yunita Nur Afifah, MNH Qomarudin and Imamatul Ummah (2020) 'Optimal Control Model Pemanenan Prey-Predator di Area Konservasi Ikan', Buana Matematika: Jurnal Ilmiah Matematika dan Pendidikan Matematika, 10(1), pp. 1-16. doi: 10.36456/buanamatematika.v10i1.2410. 
E Andryanto P/ Mechonversio, Vol. 2, No.1, Juni 2019, 9-16

Halaman Ini Sengaja Dikosongkan 